\title{
Keep Your Brain Fit! A Psychoeducational Training Program for Healthy Cognitive Aging: A Feasibility Study
}

Citation for published version (APA):

Reijnders, J., van Heugten, C., \& van Boxtel, M. (2015). Keep Your Brain Fit! A Psychoeducational Training Program for Healthy Cognitive Aging: A Feasibility Study. Educational Gerontology, 41(8), 613620. https://doi.org/10.1080/03601277.2015.1024554

Document status and date:

Published: 03/08/2015

DOI:

10.1080/03601277.2015.1024554

Document Version:

Publisher's PDF, also known as Version of record

\section{Document license:}

Taverne

\section{Please check the document version of this publication:}

- A submitted manuscript is the version of the article upon submission and before peer-review. There can be important differences between the submitted version and the official published version of record.

People interested in the research are advised to contact the author for the final version of the publication, or visit the DOI to the publisher's website.

- The final author version and the galley proof are versions of the publication after peer review.

- The final published version features the final layout of the paper including the volume, issue and page numbers.

Link to publication

\footnotetext{
General rights rights.

- You may freely distribute the URL identifying the publication in the public portal. please follow below link for the End User Agreement:

www.umlib.nl/taverne-license

Take down policy

If you believe that this document breaches copyright please contact us at:

repository@maastrichtuniversity.nl

providing details and we will investigate your claim.
}

Copyright and moral rights for the publications made accessible in the public portal are retained by the authors and/or other copyright owners and it is a condition of accessing publications that users recognise and abide by the legal requirements associated with these

- Users may download and print one copy of any publication from the public portal for the purpose of private study or research.

- You may not further distribute the material or use it for any profit-making activity or commercial gain

If the publication is distributed under the terms of Article $25 \mathrm{fa}$ of the Dutch Copyright Act, indicated by the "Taverne" license above, 


\section{Keep Your Brain Fit! A Psychoeducational Training Program for Healthy Cognitive Aging: A Feasibility Study}

\section{Jennifer Reijnders, Caroline van Heugten \& Martin van Boxtel}

To cite this article: Jennifer Reijnders, Caroline van Heugten \& Martin van Boxtel (2015) Keep Your Brain Fit! A Psychoeducational Training Program for Healthy Cognitive Aging: A Feasibility Study, Educational Gerontology, 41:8, 613-620, DOI: 10.1080/03601277.2015.1024554

To link to this article: https://doi.org/10.1080/03601277.2015.1024554

\section{Published online: 18 May 2015.}

Submit your article to this journal $\widetilde{3}$

III Article views: 423

Q View related articles

View Crossmark data \lceil

Citing articles: 1 View citing articles 지 


\title{
Keep Your Brain Fit! A Psychoeducational Training Program for Healthy Cognitive Aging: A Feasibility Study
}

\author{
Jennifer Reijnders, Caroline van Heugten, and Martin van Boxtel \\ Department of Psychiatry and Neuropsychology, Maastricht University, \\ Maastricht, the Netherlands
}

\begin{abstract}
A psychoeducational face-to-face training program (Keep Your Brain Fit!) was developed to support the working population in coping with age-related cognitive changes and taking proactive preventive measures to maintain cognitive health. A feasibility study was conducted to test the training program presented in a workshop format. Participants completed an online questionnaire immediately after the workshop and three weeks later. The questionnaire assessed participants' appreciation of the workshop and evaluation of subjective cognitive functioning. 155 men and women between 40 and 65 years old (mean age: 53.8) participated in the workshops. The results showed the participants' appreciation of the knowledge they gained by participating in the workshop. Participation reduced negative emotions toward cognitive functioning in $69 \%$ of the participants, and almost $50 \%$ indicated that they were better able to cope with cognitive challenges. This psychoeducational program may offer a valuable contribution to the coping strategies of the aging workforce. Adjustments were made based on participants' evaluations, and the program was made suitable for online use in order to reach a broader audience.
\end{abstract}

As people grow older, they increasingly encounter difficulties regarding changes in their cognitive abilities such as memory (Schaie, 1994). Such changes often lead to worry and frustration in older adults (Mol, Ruiter, Verhey, Dijkstra, \& Jolles, 2008). Continuous learning and skill development is stimulated in many workplaces due to the new development of communication and information technologies. Stenfors, Magnusson Hanson, Oxenstierna, Theorell, and Nilsson (2013) showed that information and communication technology demands are associated with increased cognitive complaints.

Much research has been devoted to the development of cognitive interventions for older adults. Recently, we showed that although older adults sometimes seem to benefit from cognitive interventions, such effects rarely generalize to other cognitive domains or everyday life activities (Reijnders, van Heugten, \& van Boxtel, 2013). It has been stressed that future interventions should increase awareness and knowledge of cognitive changes and decrease negative beliefs and negative memory-related affect about cognitive functioning (McDougall, 2009; Rebok, Carlson, \& Langbaum, 2007).

Address correspondence to Jennifer Reijnders, Faculty of Psychology and Educational Sciences, Department of Clinical Psychology, Open University, P.O. Box 2960, 6401 DL Heerlen, The Netherlands. E-mail: jennifer.reijnders@ou.nl 
Previous intervention studies focused on negative beliefs, subjective cognitive functioning, and memory self-efficacy. In a study by Valentijn et al. (2005), a memory-training program resulted in reduced feelings of anxiety and stress in relation to memory functioning in both a group training and an individual training (Valentijn et al., 2005). In a study by van Hooren et al. (2007), a goal-management training program reduced feelings of annoyance about cognitive failures and increased ability to structure activities in daily life. Cognitive training programs based on enhancing self-efficacy showed improvements in both performance and memory self-efficacy in most of the everyday memory tasks, as well as an increased control regarding the participants' own memory (Hastings \& West, 2009; West, Bagwell, \& Dark-Freudeman, 2008). In the intervention studies mentioned here, only older adults (age 54 and older) were included (Hastings \& West, 2009; Valentijn et al., 2005; van Hooren et al., 2007; West et al., 2008).

Our goal was to develop a psychoeducational training program (Keep Your Brain Fit!) aimed at the middle-aged-to-older working population (40-65 years old). This training program combined elements that were previously effective in increasing subjective cognitive functioning and memory self-efficacy (Hastings \& West, 2009; Valentijn et al., 2005; van Hooren et al., 2007; West et al., 2008). The intervention was developed in two steps. First, a feasibility study was done in which the content of the training program was tested in face-to-face workshops. Second, the content of the training program was adjusted according to participants' evaluations and made suitable for online use. The effectiveness of the online training program will be investigated in a future randomized controlled trial (RCT). In this paper, we report on the results of the feasibility study.

\section{METHODS}

\section{Participants and Procedure}

Employed people between 40 and 65 years of age were recruited from companies in the southern part of the Netherlands via intranet advertisements posted between February 2012 and December 2012. People could register online for the two-hour in-company workshop (Keep Your Brain Fit!). Workshops were all hosted by a medical doctor (MvB) and a psychologist (JR) and offered in groups of 10-to-20 participants. After the workshop, participants completed an online questionnaire assessing the participants' appreciation of the workshop and self-evaluation regarding their subjective cognitive functioning. The self-evaluation questions were again asked after three weeks.

\section{Training Program}

\section{Lifestyle \& Cognition Monitor}

One week before participating in the workshop, participants received a link to an online Lifestyle \& Cognition Monitor. This module included questions about lifestyle factors, forgetfulness, and meta-memory. Individual scores were compared to normative data derived from the Maastricht Aging Study, a longitudinal study of determinants of healthy cognitive aging (Jolles, van Boxtel, Ponds, Metsemakers, \& Houx, 1998). Participants received a result form showing their personal scores compared to the normative data in a textual and graphical format, providing 
personal feedback about factors that may affect current and future cognitive aging. The content of the monitor was discussed with the participants during the workshop.

\section{The Workshop}

The workshop itself was given in a structured manner, within a standard time frame (two hours), and consisted of three modules:

- A lifestyle module, in which a short introductory movie of 10 minutes was shown about the cognitive aging process, with a particular stress on brain plasticity. Next, evidence-based factors known to affect cognitive functioning were discussed. The following factors were included: general health, active lifestyle, social network, mood, anxiety, stress, life satisfaction, sleep and nutrition. All of these 'lifestyle' factors had been queried in the online Lifestyle \& Cognition Monitor. By filling in this monitor participants had received a personal scoring form, which gave them an indication which factors could be improved (Fernandez \& Goldberg, 2009; Jeste, Depp, \& Vahia, 2010; Lazeron \& van Dinteren, 2010).

- A memory module, which addressed the nature of memory complaints and everyday mistakes. It was stressed that both young and older people make everyday mistakes, although older people are often more worried about them. Participants were taught briefly about how memory works and about the causes of forgetfulness (for example, lack of attention or interference). Also the term memory self-efficacy was explained and how worrying about forgetfulness can lead to diminishing memory self-efficacy. Next, participants were asked to register some past memory failures in a memory diary to help them gaining insight into the possible causes of memory failures. After that, the use of internal (e.g., rehearsal, visualization) and external (e.g., agenda, to-do list) memory strategies that can help the memory system to work more efficiently were discussed and illustrated (Ponds \& Verhey, 2000).

- An effective work module, which addressed different kinds of attention (selective, divided, and sustained), situations in which attention errors often occur and strategies to improve attention (e.g., regular breaks, minimal interference). Next, an example of a planning model (goal management model) was discussed and illustrated. This model is also known as the Stop-Set-Split-Check Model, and it provides a systematic way of performing a task following the four consecutive steps (In de Braek, Dijkstra, Ponds, \& Jolles, 2012; Levine et al., 2000; Levine et al., 2007). Finally, a short summary of the three modules was given, and participants were invited to formulate future action points in writing.

\section{Measures}

After the workshop, a link was provided to an online questionnaire about appreciation of the workshop and self-evaluation questions about subjective cognitive functioning. Participants could complete this questionnaire within one week. The self-evaluation questions were again asked after three weeks. 


\section{Participants' Appreciation}

Participants graded the Lifestyle \& Cognition Monitor and the workshop on a 10-point scale and graded different subparts of the workshop on a 5-point Likert scale. Participants answered the following questions: Was the outcome of the monitor useful to you (yes/no/don't know)? Did the monitor give you insight in your personal situation related to factors influencing healthy cognitive aging (yes/no/don't know)? What did you think of the duration of the workshop (too long/fine/too short)? In addition, participants were asked to give comments about how the training program could be improved.

\section{Self-Evaluation}

Participants compared several aspects of their functioning after the training program to their functioning prior to the training program. Selected domains were the following: (a) making cognitive mistakes, (b) being hindered by cognitive mistakes, (c) being worried about cognitive abilities, (d) being afraid about becoming demented, (e) feeling able to cope with cognitive challenges. Answers were rated on a five-point scale ranging from worse than before the training to better than before the training (Hoogenhout, de Groot, \& Jolles, 2010; Hoogenhout, de Groot, van der Elst, \& Jolles, 2012). These self-evaluation questions were asked directly after participation in the workshop and again after three weeks.

\section{Statistics}

Demographic data and participants' appreciation and self-evaluation scores were analyzed by means of descriptive statistics. Independent samples $t$ tests were used to investigate whether appreciation and self-evaluation differed among men and women. To explore potential associations between other background characteristics (age, educational level) and participants' appreciation and self-evaluation, Pearson's correlation coefficients were calculated. All analyses were carried out with IBM SPSS statistics software, version 19 (SPSS, Chicago). Alpha was set at 0.05 .

\section{RESULTS}

\section{Demographic Data}

In total, 13 workshops were given with 155 participants (57 male, 98 female). Mean age was 53.8 ( $S D$ 6.7), and mean education level was 6.0 (Higher vocational education) ( $S D$ 1.4) on an eight-point scale ranging from primary school to university degree.

\section{Participants' Appreciation}

Participants' mean evaluation of the monitor was 7.3 (SD 0.9), and their mean evaluation of the workshop was $7.7(S D 0.8)$ on a 10-point scale $(n=151)$. The three subparts of the workshop 
TABLE 1

Participants' Evaluations on How to Improve the Training Program

Most frequently given comments

1. Increasing the number of exercises

2. Increasing the length of the workshop in order to explain information in more detail

3. Making the information more personal

4. Adding a list for further reading

5. Interaction with other participants

(lifestyle, memory, and effective work) were rated, respectively, as 4.0 ( $S D$ 0.5), 3.9 ( $S D$ 0.5), and $4.0(S D$ 0.5) on a 5-point scale. Most participants were satisfied with the duration of the workshop (82\%); they indicated that the monitor was useful $(78 \%)$ and provided insight into their personal situation $(70 \%)$. Most frequently given comments on how to improve the training program are summarized in Table 1.

\section{Self-Evaluation}

Of the 145 participants who filled in the self-evaluation questions directly after the training, 18 $(12.4 \%)$ indicated they made fewer cognitive mistakes than before the training. Fifty-four of the $145(37.3 \%)$ participants indicated that they were (much) less hindered by their cognitive mistakes, while $2(1.4 \%)$ participants reported more hindrance. A total of 101 of the $145(69.2 \%)$ participants indicated being (much) less worried about their cognitive abilities, and $8(5.5 \%)$ reported being more worried. Fifty-two of the $145(35.8 \%)$ participants indicated being (much) less afraid about becoming demented, and only $3(2.1 \%)$ reported being more afraid. Seventy-one of the 145 (49\%) indicated being better able to cope with cognitive challenges. One participant reported being less able to cope with cognitive challenges.

Of the 145 participants who filled in the self-evaluation questions directly after the training, 35 participants also completed the self-evaluation questions after three weeks. The percentages for the self-evaluation questions directly after the training and three weeks later are shown in Table 2.

TABLE 2

Self-Evaluations One Week and Three Weeks after Participation in the Workshop

\begin{tabular}{lcc}
\hline & \multicolumn{2}{c}{ Self-evaluations } \\
\cline { 2 - 3 } & $\begin{array}{c}\text { After participation } \\
\text { in the workshop }(n=145)\end{array}$ & Three weeks later ( $n=35$ ) \\
\hline Making (much) less cognitive mistakes & $12.4 \%$ & $28.6 \%$ \\
Being (much) less hindered about cognitive mistakes & $37.3 \%$ & $51.4 \%$ \\
Being (much) less worried about cognitive abilities & $69.2 \%$ & $79.4 \%$ \\
Being (much) less afraid about becoming demented & $35.8 \%$ & $32.4 \%$ \\
Better able to cope with cognitive challenges & $49 \%$ & $45.7 \%$ \\
\hline
\end{tabular}




\section{Participants' Characteristics in Relation to Evaluations}

Independent samples $t$ tests showed no significant differences in appreciation of the workshop between men and women $(t=-0.96, p=.92)$, and there were no significant differences on the five self-evaluation questions between men and women $(t=-1.60, p=.11 ; t=0.85$, $p=.39 ; t=-0.41, p=.67 ; t=-0.17, p=.85 ; t=0.47, p=.63)$. No significant associations were found between age and appreciation of the workshop $(r=.12, p=.14)$, between age and the five self-evaluation questions $(r=-.05, p=.54 ; r=.12, p=.14 ; r=.11, p=.19$; $r=.14, p=.09 ; r=.01, p=.86$ ), between level of education and appreciation of the workshop $(r=.05, p=.48)$ or between level of education and the (five) self-evaluation questions $(r=-.07$, $p=.34 ; r=.04, p=.61 ; r<.01, p=.97 ; r=-.14, p=.09 ; r=-.12, p=.12)$.

\section{DISCUSSION AND CONCLUSION}

\section{Discussion}

The results of this feasibility study showed that participants' appreciation of the workshop was good (grade: 7.7). Most participants were satisfied with the duration of the workshop and indicated that the Lifestyle \& Cognition Monitor was useful for providing insight into their personal situation. Results also showed that almost $50 \%$ of the participants reported being better able to cope with cognitive challenges after participating in the workshop, and participation led to reduced negative emotions toward cognitive functioning in the majority of participants $(69.2 \%)$. This percentage even increased three weeks after participating in the workshop (79.4\%), but the latter finding could be biased due to the small number of respondents after three weeks $(n=35)$. Additional analyses showed that there were no associations between appreciation of the workshop and demographical characteristics.

Based on participants' evaluations of the training program, a number of adjustments were made. First, the total amount of information was increased and a number of exercises were added: keeping a Memory Diary, practicing with memory strategies, identifying high-risk moments for attention errors, and practicing with the goal-management model. Furthermore, a personal workbook was added, which contains a summary of the information given in the training program and the exercises that participants completed. Also, a comprehensive list for further reading was added.

\section{E-Health Application}

In order to reach a much broader audience, the training program was adapted for online use. Additional adjustments were made that were especially directed at maintaining - or even increasing - the personal aspects of the training program. First, information is provided in two ways: as instructional text and in a video clip. Second, the online program was designed as a computer-generated tailored intervention. By tailoring the information based on respondent characteristics, the intervention becomes more personalized, which may increase attentiveness to the message, increase the relevance of the message, and support compliance with the online program (Dijkstra \& De Vries, 1999). Tailoring is partly based on the Lifestyle \& Cognition 
Monitor, which was tested during this feasibility study. The effectiveness of the online training program will be investigated in a RCT (Dutch trial registry: NTR 3973).

\section{Conclusion}

This feasibility study showed that the developed psychoeducational program may offer a valuable contribution to older workers in coping with age-related cognitive changes. The training program was adapted for online use in order to reach a much broader audience.

\section{ACKNOWLEDGMENTS}

We would like to thank. J. Evers, MSc, for his help in facilitating the workshops, C. Geusgens, $\mathrm{PhD}$, and prof. R. Ponds, $\mathrm{PhD}$, for their support and discussions regarding the online training program. We also would like to thank V. Cox, MSc, and prof. H. de Vries, $\mathrm{PhD}$, for their advice and support in developing the online training program and their expertise in building tailoredbased interventions.

\section{FUNDING}

This study was sponsored by the National Initiative Brain and Cognition (NIHC) and the Netherlands Organization for Scientific Research (NWO).

\section{REFERENCES}

Dijkstra, A., \& De Vries, H. (1999). The development of computer-generated tailored interventions. Patient Education and Counseling, 36(2), 193-203. doi: S0738-3991(98)00135-9 [pii]

Fernandez, A., \& Goldberg, E. (2009). The sharpbrains guide to brain fitness. San Francisco, CA: SharpBrains.

Hastings, E. C., \& West, R. L. (2009). The relative success of a self-help and a group-based memory training program for older adults. Psychology and Aging, 24(3), 586-594. doi: 2009-13203-007 [pii] 10.1037/a0016951

Hoogenhout, E. M., de Groot, R. H., \& Jolles, J. (2010). A new comprehensive educational program for older adults with cognitive complaints: Background, content, and process evaluation. Educational Gerontology, 37(1), 51-73.

Hoogenhout, E. M., de Groot, R. H., van der Elst, W., \& Jolles, J. (2012). Effects of a comprehensive educational group intervention in older women with cognitive complaints: A randomized controlled trial. Aging \& Mental Health, 16(2), 135-144. doi: 10.1080/13607863.2011.598846

In de Braek, D., Dijkstra, J., Ponds, R., \& Jolles, J. (2012). Goal management training in adults with ADHD: An intervention study. Journal of Attention Disorders. doi: 10.1177/1087054712468052

Jeste, D. V., Depp, C. A., \& Vahia, I. V. (2010). Successful cognitive and emotional aging. World Psychiatry, 9(2), $78-84$.

Jolles, J., van Boxtel, M. P., Ponds, R. W., Metsemakers, J. F., \& Houx, P. J. (1998). The Maastricht aging study (MAAS). The longitudinal perspective of cognitive aging. Tijdschrift voor Gerontologie en Geriatrie, 29(3), 120-129.

Lazeron, N., \& van Dinteren, R. (2010).Brein@Work. Houten, The Netherlands: Bohn Stafleu van Loghum.

Levine, B., Robertson, I. H., Clare, L., Carter, G., Hong, J., Wilson, B. A., ... Stuss, D. T. (2000). Rehabilitation of executive functioning: An experimental-clinical validation of goal management training. Journal of the International Neuropsychological Society, 6(3), 299-312.

Levine, B., Stuss, D. T., Winocur, G., Binns, M. A., Fahy, L., Mandic, M.,... Robertson, I. H. (2007). Cognitive rehabilitation in the elderly: Effects on strategic behavior in relation to goal management. J Int Neuropsychol Soc, 13(1), 143-152. doi: S1355617707070178 [pii] 10.1017/S1355617707070178 
McDougall, G. J., Jr. (2009). A framework for cognitive interventions targeting everyday memory performance and memory self-efficacy. Family \& Community Health, 32(1 Suppl), S15-S26. doi: 10.1097/01. FCH.0000342836.20854. fb00003727-200901001-00004 [pii]

Mol, M. E., Ruiter, R. A., Verhey, F. R., Dijkstra, J., \& Jolles, J. (2008). A study into the psychosocial determinants of perceived forgetfulness: Implications for future interventions. Aging \& Mental Health, 12(2), 167-176. doi: 791905132 [pii]10.1080/13607860801972503

Ponds, R. W. H. M., \& Verhey, F. R. J. (2000). Geheugensteun [Memory support]. Utrecht/Antwerpen, The Netherlands : Kosmos-Z\&K Uitgevers.

Rebok, G. W., Carlson, M. C., \& Langbaum, J. B. (2007). Training and maintaining memory abilities in healthy older adults: Traditional and novel approaches. Journal of Gerontology. Series B, Psychological Sciences and Social Sciences, 62 (Spec No 1), 53-61. doi: 62/suppl_Special_Issue_1/53 [pii]

Reijnders, J., van Heugten, C., \& van Boxtel, M. (2013). Cognitive interventions in healthy older adults and people with mild cognitive impairment: A systematic review. Ageing Research Reviews, 12(1), 263-275. doi: S15681637(12)00097-9 [pii] 10.1016/j.arr.2012.07.003

Schaie, K. W. (1994). The course of adult intellectual development. American Psychologist, 49(4), 304-313.

Stenfors, C. U., Magnusson Hanson, L., Oxenstierna, G., Theorell, T., \& Nilsson, L. G. (2013). Psychosocial working conditions and cognitive complaints among Swedish employees. PLoS One, 8(4), e60637. doi: 10.1371/journal. pone. 0060637

Valentijn, S. A., van Hooren, S. A., Bosma, H., Touw, D. M., Jolles, J., van Boxtel, M. P., \& Ponds, R. W. (2005). The effect of two types of memory training on subjective and objective memory performance in healthy individuals aged 55 years and older: A randomized controlled trial. Patient Education and Counseling, 57(1), 106-114. doi: S0738399104001466 [pii] 10.1016/j.pec.2004.05.002

van Hooren, S. A., Valentijn, S. A., Bosma, H., Ponds, R. W., van Boxtel, M. P., Levine, B., . . Jolles, J. (2007). Effect of a structured course involving goal management training in older adults: A randomised controlled trial. Patient Education and Counseling, 65(2), 205-213. doi: S0738-3991(06)00249-7 [pii]10.1016/j.pec.2006.07.010

West, R. L., Bagwell, D. K., \& Dark-Freudeman, A. (2008). Self-efficacy and memory aging: The impact of a memory intervention based on self-efficacy. Neuropsychology, Development, and Cognition. Section B, Aging, Neuropsychology and Cognition, 15(3), 302-329. doi: 10.1080/13825580701440510 